\title{
A Discussion of Water in the Crust
}

\section{Peter J. Wyllie}

Department of Geophysical Sciences, University of Chicago, Chicago, Illinois 60637

This comment was stimulated by the suggestion that a geochemist discuss the possibility that water is present in the crust. This material is relevant to the papers of $\mathrm{T}$. Madden and W. F. Brace.

Wyllie: I do not know what actually happens to water in the crust, but I can outline the conditions and variables that we are concerned with and the types of theoretical and experimental systems that provide limits for the natural conditions.

Significant variables in the crust are composition, mineralogy, temperature $(T)$, pressure as a function of depth $\left(P_{t}=P_{\text {total }}\right)$, the pressure on the interstitial pore fluid if present $\left(P_{f}\right)$, and the partial pressures of the pore fluid components. A rock in the crust may consist of any combination of anhydrous minerals, hydrous minerals, and a pore fluid generally considered to be dominantly aqueous. Let us arbitrarily omit carbonates for simplicity. Changes in depth and temperature cause reactions to occur among the rock components. For example, increasing temperature may cause dehydration of a hydrous mineral such as brucite:

$$
\mathrm{Mg}(\mathrm{OH})_{2}=\mathrm{MgO}+\mathrm{H}_{2} \mathrm{O}
$$

releasing $\mathrm{H}_{2} \mathrm{O}$ to the pore fluid.

I have listed on the board five possible conditions for a rock in the crust. First, .

$$
P_{f}=P_{\mathrm{H}_{2} \mathrm{O}}=P_{t}
$$

This assumes that the pore fluid is composed essentially of pure $\mathrm{H}_{2} \mathrm{O}$. Second,

$$
P_{f}=P_{\mathrm{H}_{2} \mathrm{O}}<P_{t}
$$

This refers to a rock in which the pore fluid is composed of pure $\mathrm{H}_{2} \mathrm{O}$, but part of the lithostatic pressure is supported by grain-to-grain boundary contacts, and there just isn't enough fluid in the rock to fill the available pore space and reach the confining pressure. Third,

$$
P_{\mathrm{H}_{2} \mathrm{O}}<P_{\mathrm{f}}=P_{\mathrm{t}}
$$

This occurs in a rock in which $P_{\mathrm{H}_{2} \mathrm{O}}$ is reduced compared with $P_{f}$ because the fluid phase is diluted by other components in solution, such as $\mathrm{CO}_{2}$ and alkali salts. Fourth,

$$
P_{f}=0 ; \quad P_{\mathrm{H}_{2} \mathrm{O}}<P_{t}
$$

This condition occurs if there is no pore fluid present in the rock at all. $P_{\mathrm{H}_{2} \mathrm{O}}$ may still have a finite, fictive value if the vapor-absent rock consists of both hydrous and anhydrous minerals. Fifth,

$$
P_{f}>P_{t}
$$

These conditions can be illustrated using phase diagrams for the system $\mathrm{MgO}-\mathrm{H}_{2} \mathrm{O}$, which is about the simplest system involving examples of anhydrous minerals, hydrous minerals, and a vapor phase (= pore fluid). In Figure 1a, I have sketched a $P-T$ diagram for the univariant dissociation reaction under condition 1 , with $P_{f}=P_{\mathrm{H}_{2} \mathrm{O}}=P_{t} ;$ in Figure $1 b, \mathrm{I}$ have sketched an isobaric section through the system which shows the phase assemblage $\mathrm{Mg}(\mathrm{OH})_{2}+$ vapor reacting to yield $\mathrm{MgO}+$ vapor under the same condition 1 and another field for the vapor-absent assemblage $\mathrm{MgO}+\mathrm{Mg}(\mathrm{OH})_{2}$, corresponding to condition 4.

There are two types of systems that can be treated with thermodynamic rigor-a closed system and an open system. In a closed system, no material is lost or gained during a reaction. In an open system, certain components may migrate into or from the reacting system, in response to defined controls outside of the system: these are called perfectly mobile components. Rock systems in the crust may be 
treated as if they correspond to one or the other of these ideal thermodynamic systems, but in reality the natural rock systems probably behave in some intermediate fashion. Kinetic factors such as the rates of reaction and the rate of migration of pore fluids are involved in the crust, but thermodynamics tells us only about equilibrium conditions once they have been achieved.

The concept of a closed system as applied to a rock in the crust is a familiar one, but it is doubtful whether any rock is completely closed to the movement of pore fluids. The concept of an open system as applied to the kind of rock that we are using as an example requires that $\mathrm{H}_{2} \mathrm{O}$ be able to migrate in or out of the rock, through the pore fluid; the chemical potential of $\mathrm{H}_{2} \mathrm{O}$ in the open rock system is controlled by the regional chemical potential gradient appropriate for the crustal megasystem enclosing the rock system being considered. $P_{\mathrm{H}_{2} \mathrm{O}}$ is thus determined independently of the reactions occurring in the system, in contrast to the closed system where $P_{\mathrm{H}_{2} \mathrm{O}}$ is a dependent variable. In an open system, $\mathrm{H}_{2} \mathrm{O}$ is termed a mobile component. It is doubtful whether any rock system comprising a substantial volume in the crust behaves as an ideal open system, with $\mathrm{H}_{2} \mathrm{O}$ as a perfectly mobile component.

We have already considered the dissociation of brucite in a closed system, using the phase diagrams, Figure 1. The univariant curve on the $P-T$ projection gives the maximum stability temperature for brucite, for condition 1 where $P_{f}=P_{\mathrm{H}_{3} \mathrm{O}}=P_{\imath}$. The reaction temperature becomes lower at constant $P_{t}$ if $P_{\mathrm{H}_{2} \mathrm{O}}$ is reduced compared with $P_{t}$. This is achieved in a closed system if there are components additional to $\mathrm{H}_{2} \mathrm{O}$ in the vapor phase, which corresponds to condition $3, P_{\mathrm{H}_{2} \mathrm{O}}<P_{f}=P_{t}$. It is also achieved physically in a closed system with condition 2, $P_{f}<P_{t}$. A third way for the dissociation temperature to be reduced at constant $P_{f}$ is in an open system, where $P_{\mathrm{H}, \mathrm{O}}$ can be lowered independently of $P_{t}$ by factors external to the system. So we see that the products of a particular dissociation reaction at a given depth in the crust are not produced simply because the appropriate temperature is reached; they may be produced at various temperatures depending on the pore fluid composition and behavior. For this reason, it is very difficult to deduce the nature of the pore fluid in a rock from the study of its mineralogy. Notice again the water-deficient a

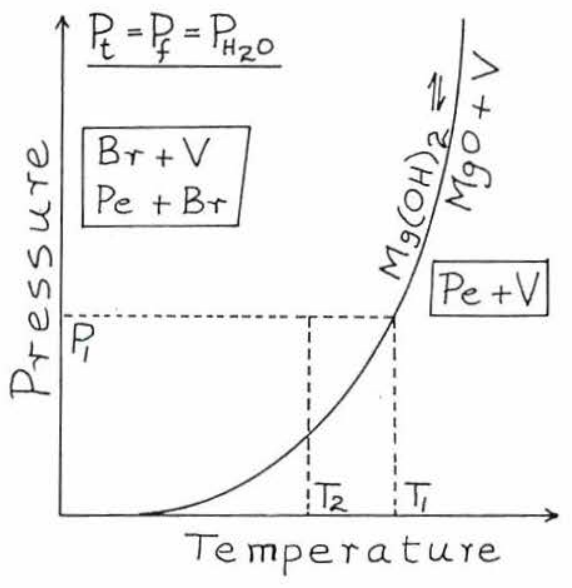

$b$

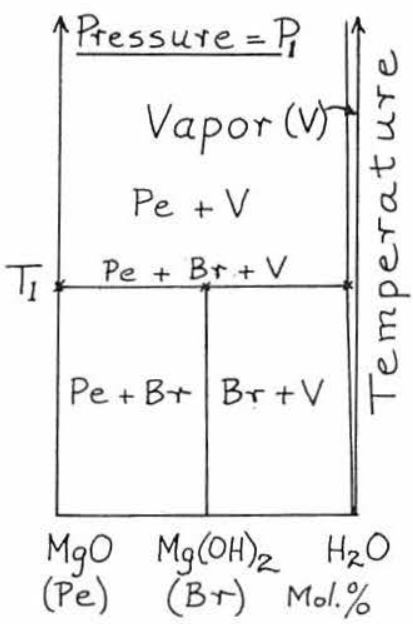

Fig. 1. Phase relationships in the system $\mathrm{MgO}-\mathrm{H}_{2} \mathrm{O}$. $1 a$ shows a univariant curve for the dissociation of brucite $(\mathrm{Br})$ in the presence of a vapor phase $(\mathrm{V})$ composed of pure water, to yield periclase $(\mathrm{Pe})$ and vapor. The phase assemblages stable at temperatures above and below the conditions for reaction are shown. These can be seen on Figure 1b. Irobaric section through the system at pressure $P_{1}$ from Figure $1 a$. Notice the vapor-absent field for periclase plus brucite. Brucite becomes unstable at temperature $T_{1}$ (see Figure 1a). 
region in the isobar for the system $\mathrm{MgO}-\mathrm{H}_{2} \mathrm{O}$; if no vapor phase is present, the assemblage brucite + periclase exists at temperatures well below the brucite dissociation temperature. If there is insufficient $\mathrm{H}_{2} \mathrm{O}$ in the system to cause the maximum hydration of $\mathrm{MgO}$, then no vapor phase exists.

Healy: Are you saying that in a normal crust we'd be in a non-vapor phase region?

Wyllie: No In the crust we could have a free vapor phase, but the phase diagrams show also that a vapor-absent phase assemblage is theoretically possible.

We can extend the simple $\mathrm{MgO}-\mathrm{H}_{2} \mathrm{O}$ system to provide an illustration of processes in open systems. If we add a non-reacting volatile component $X$, we can use a triangle $\mathrm{MgO}-\mathrm{H}_{2} \mathrm{O}-X$, Figure 2, to show the phase relationships at constant $P_{t}$ and constant temperature. We can lower $P_{\mathrm{H}_{2} \mathrm{O}}$ from its maximum value in $\mathrm{MgO}-\mathrm{H}_{2} \mathrm{O}$ by diluting the vapor phase with the additional material $X$. At a given $P_{t}$ and $T$, the two minerals brucite + periclase coexist with a vapor phase of fixed composition. The assemblage can be hydrated to yield brucite or dehydrated to yield periclase just by changing the vapor phase composition at constant $P_{t}$ and $T$. This is what can happen in an open system, when the regional chemical potential gradient for $\mathrm{H}_{2} \mathrm{O}$ causes $\mathrm{H}_{2} \mathrm{O}$ to migrate into or out of the rock. (This topic was discussed in more detail, following Wyllie $[1962 a, b])$.

I want to call your attention in particular to the assemblage brucite + periclase + vapor in the ternary system. What we have done is to add a mixed vapor phase, $\mathrm{H}_{2} \mathrm{O}-X$, to the vapor-absent region of the binary system $\mathrm{MgO}-\mathrm{H}_{2} \mathrm{O}$. The assemblage is still water-deficient, because it is not saturated with $\mathrm{H}_{2} \mathrm{O}$. Imagine this assemblage in an open system, and assume that water starts leaking into the system. It will not change the vapor phase composition because it will be used up by reaction, producing brucite, if equilibrium is maintained, so that the water will not be able to migrate freely through the system. It has to pass through the system as a front. It converts all of the periclase to brucite in each small volume before whatever remains is able to pass through the system, changing the vapor phase composition. There was a question this morning about how water coming into a rock would get soaked up. If the mineralogy of the rock is unsaturated with $\mathrm{H}_{a} \mathrm{O}$, then $\mathrm{H}_{9} \mathrm{O}$ cannot

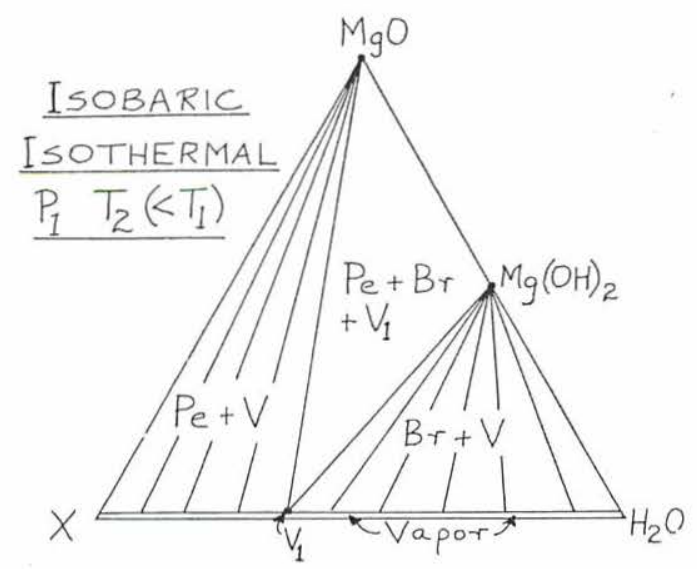

Fig. 2. Phase relations in the system $\mathrm{MgO}$ $\mathrm{H}_{2} \mathrm{O}-X$ where components $X$ are non-reacting components soluble in the aqueous fluid (vapor $=\mathrm{V})$ phase. An isobaric isothermal section through the system at pressure $P_{1}$ and temperature $T_{2}$ from Figure $1 a$. Figure $1 b$ shows that in the presence of $\mathrm{H}_{2} \mathrm{O}$ at constant pressure, periclase and brucite coexist at only one temperature $\left(T_{1}\right)$. If the vapor phase is diluted with components $X$, as in this figure, then these two minerals coexist with a specific vapor phase $V_{1}$ at a lower temperature $T_{2}$. The reaction $\mathrm{Mg}(\mathrm{OH})_{2}$ $\rightleftharpoons \mathrm{MgO}+\mathrm{H}_{2} \mathrm{O}$ can be made to occur at constant total pressure $\left(P_{t}\right)$ and constant temperature $\left(T_{2}\right)$ by diluting the vapor phase with $X$.

pass through it without first reacting to saturate the minerals, to the extent required by the conditions of $P_{1}$ and $T$. This assumes, of course, that chemical equilibrium is maintained.

Madden: For a given temperature, is there no water pressure at which a fluid phase would be present without being absorbed into the minerals?

Wyllie: If the bulk composition of a rock is unsaturated with $\mathrm{H}_{3} \mathrm{O}$ for the given conditions of $T$ and $P_{t}$, then any additional $\mathrm{H}_{2} \mathrm{O}$ would have to react with the minerals until saturation were complete, and during this process $P_{\mathrm{H}_{2} \mathrm{O}}$ would be buffered by the mineral assemblage.

Madden: No matter what the water pressure is, even if it is at zero pressure?

Wyllie: Pore fluid with zero water pressure; that would be composed of $\mathrm{CO}_{2}$, for example, and certainly you could pass $\mathrm{CO}_{2}$ through the rock without its reacting (unless carbonation reactions become involved).

Madden: No, I mean supposing it was a pore fluid, but with very low water pressure.

Wyllie: The phase diagram and other phase diagrams for more complex systems indicate 
that a pore fluid with very low water pressure could exist with an anhydrous mineral assemblage. If $\mathrm{H}_{2} \mathrm{O}$ were added to the system, the pore fluid composition would change and $P_{\mathrm{H}_{2} \mathrm{O}}$ would increase until the hydrous minerals began to form, and thereafter additional $\mathrm{H}_{2} \mathrm{O}$ would react, with $P_{\mathrm{H}_{2} \mathrm{O}}$ buffered by the minerals, until the rock became saturated with $\mathrm{H}_{2} \mathrm{O}$ and no more hydrous minerals could be produced. Only then could more $\mathrm{H}_{2} \mathrm{O}$ be added to the rock without being absorbed by the minerals.

The phase diagram for the system $\mathrm{MgO}-\mathrm{H}_{2} \mathrm{O}$ shows that if you have a vapor-absent $\mathrm{H}_{2} \mathrm{O}$ undersaturated rock, then you can add $\mathrm{H}_{2} \mathrm{O}$ to the system without producing any pore fluid at all until all of the anhydrous minerals are fully hydrated.

Madden: No matter what the pressure is?

Wyllie: Yes, as long as you start off with a vapor-absent rock and $\mathrm{H}_{2} \mathrm{O}$-undersaturated mineral assemblage, and this condition is theoretically possible. Whether it ever occurs in the crust is another question.

Madden: Well, you're telling us then that you can look at a rock and tell us that actually there could have been no water whatsoever no matter what the fluid pressure was?

Wyllie: No, I don't think you can do this. The phase diagrams show that a mineral assem- blage that is $\mathrm{H}_{2} \mathrm{O}$-unsaturated can exist either without any pore fluid at all or with a pore fluid present.

Madden: Another question is Are the pore fluids common in certain crustal environments?

Wyllie: I started out by saying that I don't know what the actual regime of water is in the crust. The phase diagrams do not tell us this; they only show conditions that are possible in the crust, if chemical equilibrium is achieved. I would guess that there is a pore fluid present in most parts of the crust.

Healy: You can't rule out free water.

Wyllie: The phase diagrams show that the same mineral assemblage can exist either with or without a pore fluid, so study of mineralogy is not sufficient to tell you whether or not a pore fluid containing $\mathrm{H}_{2} \mathrm{O}$ is present. It seems to me that an aqueous pore fluid could exist in equilibrium with any known crustal rock, provided that conditions of $P_{t}, P_{t}$, and $T$ are suitable.

\section{REFERENCES}

Wyllie, P. J., The petrogenetic model, an extension of Bowen's petrogenetic grid, Geol. Mag., 99, 558-569, 1962a.

Wyllie, P. J., The effect of 'impure' pore fluids on metamorphic dissociation reactions, Mineral. Mag., 33, 9-25, $1962 b$. 


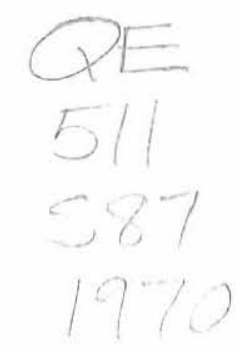

geophysical monograph 14

\section{The Structure and Physical}

\section{Properties of the Earth's Crust}

JOHN G. HEACOCK editor

American Geophysical Union

Washington, D. C.

1971 